\title{
Pancreatectomía central en tumores benignos del cuello del páncreas
}

\author{
Víctor Valenti-Azcarate ${ }^{\mathrm{a}}$, Fernando Pardo-Sánchez ${ }^{\mathrm{a}}$, Fernando Rotellar-Sastre ${ }^{\mathrm{a}}$, Aurora Gil-Rendo ${ }^{\mathrm{a}}$, \\ María Cervera-Delgado ${ }^{\text {, Carlos Pastor-Idoate }}{ }^{a}$, Ignacio Poveda-Laceras ${ }^{a}$, Juan José Beunza-Nuin ${ }^{b}$ \\ y Javier Álvarez-Cienfuegos ${ }^{a}$ \\ ${ }^{a}$ Cirugía General. Clínica Universitaria de Navarra. Pamplona. Navarra. \\ bedicina Interna. Clínica Universitaria de Navarra. Pamplona. Navarra. España.
}

\section{Resumen}

El tratamiento quirúrgico de los tumores benignos del cuello del páncreas ha sido clásicamente la enucleación o la pancreatectomía estándar. La pancreatectomía central se ha propuesto por su menor tasa de complicaciones y por la posibilidad de preservar la función endocrina y exocrina.

Entre enero de 1999 y marzo de 2003 se realizaron en nuestro centro 3 pancreatectomías centrales por patología benigna en el cuello del páncreas. En todos los casos se realizó tomografía computarizada, ecografía intraoperatoria y estudio anatomopatológico. El examen de las piezas quirúrgicas mostró 2 cistoadenomas mucinosos y 1 cistoadenoma seroso. Ninguno de los pacientes presentó complicaciones quirúrgicas mayores, recurrencia local de la enfermedad o diabetes, con un seguimiento medio de 34 meses.

Podemos decir, por tanto, que la pancreatectomía central es una técnica útil para un grupo seleccionado de pacientes con lesiones benignas en el cuello del páncreas o de bajo grado de malignidad.

Palabras clave: Pancreatectomía central. Tumores benignos de páncreas. Cistoadenoma.

\section{CENTRAL PANCREATECTOMY IN BENIGN TUMORS OF THE NECK OF THE PANCREAS}

The surgical treatment of benign tumors of the neck of the pancreas usually consists of enucleation or formal pancreatectomy. Central pancreatectomy has been put forward because it has fewer major complications and can preserve endocrine and exocrine function.

Between January 1999 and march 2003, three patients with benign tumors of the neck of the pancreas underwent central pancreatectomy. all patients underwent computed tomography scans, intraoperative ultrasound and frozen-section analysis. pathologic examination showed two mucinous cystadenomas and one serous cystadenoma. after a mean follow-up of 34 months, none of the patients has shown major complications or local recurrence, or has developed diabetes. In conclusion, central pancreatectomy is a useful technique for selected benign or low-grade malignant pancreatic tumors of the neck of the pancreas.

Key words: Central pancreatectomy. Benign pancreatic tumors. Cystoadenoma.

\section{Introducción}

El tratamiento quirúrgico de los tumores localizados en el cuello del páncreas no subsidiarios de enucleación ha sido clásicamente las pancreatectomía estándar (duodenopancreatectomía y pancreatectomía distal ampliada).

Correspondencia: Dr. V. Valenti-Azcarate.

Clínica Universitaria de Navarra.

Avda. Pío XII, 36. 31008 Pamplona. Navarra. España.

Manuscrito recibido el 28-10-2004 y aceptado el 1-4-2005.
Este tipo de cirugías se asocia a una alta morbilidad cau sando con frecuencia dificultad para el vaciamiento gástrico, síndrome de dumping, intolerancia a la glucosa, infección postesplenectomía y alteraciones en la función endocrina y exocrina pancreática. En los pacientes con lesiones benignas o de bajo potencial de malignidad en el cuello o cuerpo del páncreas, se ha propuesto la pancreatectomía central con el fin de evitar resecciones amplias innecesarias, preservando así la función pancreática y la integridad del tracto gastrointestinal ${ }^{1-3}$.

La pancreatectomía central también es conocida con esta otra terminología: pancreatectomía limitada conservadora, pancreatectomía segmentaria o pancreatectomía medial ${ }^{3,4}$. Son pocas las series descritas en la bi- 
TABLA 1. Serie pancreatectomía central

\begin{tabular}{ccclc}
\hline Caso & Edad & Sexo & Clínica & Histología \\
\hline 1 & 51 & V & $\begin{array}{l}\text { Asintomático, hallazgo incidental en tomografía computarizada } \\
\text { Dolor epigástrico }\end{array}$ & Cistoadenoma seroso \\
2 & 38 & M & $\begin{array}{l}\text { Pérdida de peso. Fiebre } \\
\text { Dolor epigástrico } \\
\text { Náuseas y vómitos }\end{array}$ & Cistoadenoma mucinoso \\
3 & 76 & $\mathrm{M}$ & Cistoadenoma mucinoso \\
\hline
\end{tabular}

bliografía, y en la actualidad no llegan al centenar de casos. El propósito de este estudio es valorar nuestra experiencia en la pancreatectomía central, con la descripción de 3 pacientes diagnosticados de enfermedad benigna tumoral ( 2 cistoadenomas mucinosos y 1 cistoadenoma seroso), valorando los resultados a corto y largo plazo, así como realizar una revisión de la bibliografía.

\section{Material y métodos}

En el período comprendido entre enero de 1999 y marzo de 2003 se realizaron en nuestro centro 3 pancreatectomías centrales por enfermedad benigna en el cuello o el cuerpo del páncreas. Dos cistoadenomas mucinosos y un cistoadenoma seroso. Se describen mediante casos clínicos las características de estos pacientes (tabla 1).

\section{Caso 1}

Varón de 51 años, asintomático. En estudio realizado por su médico de empresa se encuentra como hallazgo casual en tomografía computarizada (TC) una tumoración quística bien delimitada de $4 \times 4,5 \mathrm{~cm}$ en el cuello del páncreas, condicionando dilatación del Wirsung proximal a la lesión compatible con adenoma quístico. Ante estos hallazgos se recomienda la extirpación quirúrgica, realizándose pancreatectomía central y reconstrucción mediante pancreaticoyeyunostomía terminoterminal retrocólica en "Y" de Roux. El examen histológico intraoperatorio reveló la presencia de una lesión tumoral benigna acinar y la ecografía intraoperatoria descartó la presencia de otras lesiones adyacentes o anomalías anatómicas. El examen histológico definitivo fue informado de cistoadenoma seroso.

El paciente fue dado de alta al séptimo día del postoperatorio, con una buena tolerancia de una dieta oral completa. Dieciocho meses después, el paciente se encuentra asintomático sin alteraciones en la función endocrina y exocrina pancreática.

\section{Caso 2}

Mujer de 38 años, con historia de 3 meses de evolución de dolor epigástrico recurrente, pérdida de $6 \mathrm{~kg}$ de peso y fiebre. En ecografía abdominal se apreció nódulo de aspecto quístico de $16 \mathrm{~mm}$ en cuello de páncreas, imagen calcificada en conducto de Wirsung en probable relación con tumoración y colelitiasis. Dichos hallazgos fueron correlacionados con TC abdominal. Previa resección en quirófano se realizó ecografía intraoperatoria para valoración in situ de la tumoración y localización de calcificación que resultó ser una microlitiasis. El estudio histológico de las muestras intraoperatorias descartó malignidad. Se realizó pancreatectomía central con pancreaticoyeyunostomía término-terminal en "Y" de Roux y cierre del muñón cefálico y conducto de Wirsung con puntos sueltos de material irreabsorbible; asimismo, se procedió a realizar colecistectomía. El postoperatorio transcurrió con normalidad y fue dada de alta al sexto día tolerando bien la dieta oral y sin alteraciones analíticas. El diagnóstico anatomopatológico definitivo fue de cistoadenoma mucinoso pancreático. Tres años y medio después no ha presentado síntomas recurrentes.

\section{Caso 3}

Mujer de 76 años aquejada de dolor epigástrico irradiado a espalda, anorexia, náuseas y vómitos ocasionales. En ecografía realizada se observó una imagen quística tumoral de $3 \mathrm{~cm}$ en cuerpo de páncreas de la que se realizó punción con control de TC y examen citológico resultando tumor quístico de páncreas. Ante estos hallazgos y con la sintomatología acompañante se decidió intervención quirúrgica. La ecografía intraoperatoria no reveló otras lesiones y el estudio histológico confirmó la presencia de una lesión quística benigna. Se realizó pancreatectomía central con cierre del muñón cefálico del páncreas y pancreatoyeyunostomía del muñón pancreático distal con anastomosis entre Wirsung y mucosa yeyunal con puntos sueltos de material irreabsorbible y tutor perdido. Durante el postoperatorio presentó valores de amilasa de $1.500 \mu / l$. Sin embargo, la paciente no presentó signos clínicos de pancreatitis, y los valores de amilasa volvieron a la normalidad al séptimo día. Fue dada de alta en el noveno día. El diagnóstico definitivo fue informado de cistoadenoma mucinoso. Tras un seguimiento de tres años y medio no se han observado alteraciones relacionadas con su intervención.

\section{Técnica quirúrgica}

Se comienza la intervención por medio de una laparotomía subcostal bilateral. Se diseca el epiplón menor y la cara anterior del páncreas se expone. La ecografía intraoperatoria es útil para valorar las relaciones anatómicas de la lesión con las estructuras vasculares, conducto pancreático principal y descartar otras lesiones adyacentes. La arteria esplénica se libera y la arteria dorsal del páncreas junto con otras colaterales menores se ligan. La cara posterior del páncreas se diseca del eje portomesentérico y se ligan las múltiples colaterales presentes. Se realiza transección de la cabeza pancreática y el cierre con sutura aproximando la cápsula anterior y posterior, previa ligadura del conducto de Wirsung. Se moviliza el páncreas situado a la izquierda de la tumoración y se realiza nueva transección con márgenes libres de tumor. La reconstrucción se hace por medio de una pancreaticoyeyunostomía término-terminal o término-lateral en "Y" de Roux con o sin tutor.

\section{Discusión}

Los tumores benignos superficiales y de pequeño tamaño localizados en el cuello del páncreas o en las porciones próximas a la cabeza o al cuerpo del mismo son habitualmente enucleados. Aquellos en que el tamaño es mayor de $2 \mathrm{~cm}$, o cuando se encuentran englobados en el parénquima pancreático, la enucleación puede ser problemática causando daño del conducto de Wirsung al realizar la transección ${ }^{3}$. Por otro lado, las pancreatectomías ampliadas (duodenopancreatectomía cefálica o pancrea- 
tectomía distal) pueden resultar demasiado agresivas en términos de mayor morbimortalidad y alteración en la función endocrina y exocrina del páncreas. Por este motivo, Guillemin y Bessot en 1957 diseñaron la pancreatectomía central, considerando una cirugía que preservara el mayor parénquima pancreático posible y erradicara la enfermedad pancreática ${ }^{5}$. Desde entonces esta técnica ha sido utilizada por diversos autores ${ }^{2,3,6}$. Las indicaciones específicas para el uso de esta técnica incluyen las siguientes: lesiones pequeñas, generalmente menores de $5 \mathrm{~cm}$ de diámetro, tumores benignos (cistoadenoma mucinoso o seroso) o de bajo potencial de malignidad (insulinomas, tumores mucinosos, tumores cisticopapilares sólidos o tumores islet celulares no funcionantes), lesiones en el cuello del páncreas o en sus porciones contiguas y longitud del muñón pancreático remanente adecuado para la realización de la pancreaticoyeyunostomía ${ }^{3}$.

El diagnóstico preoperatorio correcto de estos tumores es indispensable para la aplicación de estos criterios. La ecografía abdominal o la TC son las pruebas de imagen más útiles inicialmente, aunque también puede ser útil la resonancia magnética (RM) si persiste la duda. Los cistoadenomas se presentan habitualmente como tumoraciones polilobuladas formadas por múltiples quistes de pequeño tamaño con calcificaciones centrales que le dan aspecto de panal de abeja ${ }^{7}$. En el $10-38 \%$ de los casos se observan cicatrices centrales en forma de estrella debido a los septos fibrosos. Estas imágenes se consideran patognomónicas ${ }^{8}$. En nuestro caso a todos los pacientes se les realizó ecografía y TC abdominal, identificando las lesiones en todos los pacientes correctamente. La punción-aspiración guiada por ecografía se ha venido usando frecuentemente; sin embargo, no existen datos que confirmen su utilidad en todos los casos ${ }^{1}$. La ecografía intraoperatoria se utilizó en los 3 pacientes para confirmar los hallazgos preoperatorios con el quirófano. No se evidenciaron en ese momento otras lesiones pancreáticas adyacentes 0 alteraciones en el conducto pancreático distal que impidieran la realización de esta técnica. El examen microscópico intraoperatorio es esencial para confirmar el carácter benigno de la lesión y la existencia de márgenes libres de tumor. En caso de malignidad es preciso abandonar esta técnica y realizar una resección oncológica completa bien sea una duodenopancreatectomía o esplenopancreatectomía distal según las características particulares de cada caso. Es preciso de todos modos esperar el diagnóstico patológico definitivo que confirme los hallazgos intraoperatorios. Tampoco conviene realizar la pancreatectomía central cuando el cuerpo y la cola del páncreas reciben flujo arterial exclusivamente de la arteria transversa pancreática (rama izquierda de la arteria pancreática dorsal), pues la sección de estos vasos puede producir necrosis del cuerpo y cola pancreáticos. Esta alteración anatómica puede ser visualizada en el quirófano al observar ausencia de colaterales de la arteria esplénica, sin necesidad de realizar una arteriografía preoperatoria ${ }^{3}$.

La extensión de la resección depende del tamaño tumoral. El muñón cefálico es suturado o grapado con material irreabsorbible dependiendo de la experiencia personal. En nuestro caso se aplicaron puntos sueltos aproximando la cápsula posterior a la anterior previa identificación y ligadura del conducto pancreático. La reconstrucción del muñón distal se realiza con asa yeyunal retrocólica en "Y" de Roux y anastomosis terminoterminal o terminolateral. Como otros autores ${ }^{2}$ utilizamos un tutor para el conducto pancreático, aunque este hecho no es seguido por todos.

Son pocas las complicaciones descritas con esta técnica cuando se comparan con las resecciones pancreáticas clásicas. La mortalidad operatoria en nuestro estudio, al igual que en otras series, es nula ${ }^{1,2,6,9}$. Aunque no hemos encontrado complicaciones mayores postoperatorias éstas están descritas hasta en un $24,7 \%$ de los casos (rango, 0-40\%) 1,2,6,9. Las más frecuentes son las fístulas pancreáticas $(10,6 \%)$ y los quistes peripancreáticos 0 abscesos $(8,2 \%)$. El riesgo potencial de producirse fugas o fístulas tanto del muñón proximal como de la pancreaticoyeyunostomía no debe obstaculizar la realización de esta técnica, puesto que en la mayoría de los casos se resuelven de modo conservador, si bien se han descrito reintervenciones por este motivo ${ }^{1}$. Por otra parte, la preservación del bazo hace que se minimicen los problemas derivados de su extirpación como son la sepsis y las alteraciones hematológicas ${ }^{10}$. La preservación de los vasos esplénicos, por tanto, resulta importante para evitar el infarto esplénico.

En conclusión, la pancreatectomía central resulta ser una técnica útil para el tratamiento de los tumores benignos o de bajo grado de malignidad del cuello del páncreas. La correcta valoración preoperatoria y la aplicación de las indicaciones establecidas hacen que sea una intervención idónea para un grupo seleccionado de pacientes. Este procedimiento permite preservar la función endocrina y exocrina pancreática con un índice de complicaciones menor al de las pancreatectomías clásicas.

\section{Bibliografía}

1. Rotman N, Satre B, Fagniez PL. Medical pancreatectomy for tumors of the neck of the pancreas. Surgery. 1993;113:532-5

2. Ikeda S, Matsumoto S, Maeshiro K, et al. Segmental pancreatectomy for the diagnosis and treatment of small lesions in the neck or body of the pancreas. Hepatogastroenterology. 1995;42:730-3.

3. Iacono C, Bortolasi L, Serio G. Is there a place for central pancreatectomy in pancreatic surgery. J Gastroentest Surg. 1998;2:509-17.

4. Fanigez PL, Kracht M, Rotman N. Limited conservative pancreatectomy for benign tumors of the pancreas. Br J Surg. 1998;75:719.

5. Guillemin P, Bessot M. Pancreatite chronique calcifiante chez un tuberculeux renal: pancreato-jejunostomie selon un technique originale. Mem. Acad. Chirurg. 1957;83:869-71.

6. Warshaw AL, Rattner DW, Fernandez del Castillo C, et al. Middle segment pancreatectomy. A novel technique for conserving pancreatic tissue. Arch Surg. 1998;133:327-31.

7. Kloppel G, Kormohl M. Cystic lesions and neoplasms of the pancreas. The features are becoming clearer. Pancreatology. 2001;1:64855

8. Combalai N, Semelca RC. Radiologie features of cystic, endocrine and other pancreatic neoplasms. Eur J Radiol. 2001;38:113-9.

9. Sperti C, Pasquali C, Ferronato A, Pedrazzoli S. Median pancreatectomy for tumors of the neck and body of the pancreas. J Am Coll Surg. 2000;190:711-5.

10. Ziemski JM, Rudowski WJ, Jaskowiak W, et al. Evaluation of early postplenectomy complications. Surg Gynecol Obstet. 1987;165: 507-14. 